\title{
Effect of Room Temperature Ionic Liquids for Electroless Nickel Plating on Acrylonitrile Butadiene Styrene Plastic
}

\author{
Canan URAZ ${ }^{1 *}$ \\ Ege University, Faculty of Engineering, Chemical Engineering Department, 35100 Bornova-İzmir, Turkey \\ cross $^{\text {ref }}$ http://dx.doi.org/10.5755/j01.ms.25.3.20116
}

Received 07 February 2018; accepted 16 July 2018

\begin{abstract}
In this study, electroless nickel (EN) plating on acrylonitrile butadiene styrene (ABS) engineering plastic using room temperature ionic liquids (RTIL) was studied. Electroless plating is a fundamental step in metal plating on plastic. This step makes the plastic conductive and makes it possible to a homogeneous and hard plating without using any hazardous and unfriendly chemical such as palladium, tin, etc. In the industry there are many distinct chemical materials both catalysts and activation solutions for the electroless bath which is one of the most important parts of the process. In this study the effects of the ionic liquid, plating time, and sand paper size were investigated on electroless nickel plating. The etching and the plating processes were performed with environmentally friendly chemicals instead of the chromic and sulphuric acids used in the traditional processes. Experiments were carried out with and without ionic liquid, EMIC, 1-ethyl-3methyl imidazolium chloride $\left(\mathrm{C}_{6} \mathrm{H}_{11} \mathrm{~N}_{2} \mathrm{Cl}\right)$, and with 400,500 and 800 grit sandpaper with the application of the sand attrition process and 70,80 , and $90^{\circ} \mathrm{C}$ bath temperatures with 30,60 , and 90 minutes of deposition time. The surface morphology and the thickness of deposit analysis were performed using the Fischer scope X-Ray XDL-B System, X-ray Diffraction (XRD), and Scanning Electron Microscopy (SEM). Due to the results of the experiments and analysis, the electroless nickel plating on ABS plastic was a success. The best plating was obtained at $5.010 \mu \mathrm{m}$ as the maximum plating thickness, at $90 \mathrm{~min}$ of plating time and $80{ }^{\circ} \mathrm{C}$ as the plating bath temperature for electroless nickel plating on $\mathrm{ABS}$ plastic whit the surface activated with 800 grit sandpaper using EMIC ionic liquid.

Keywords: ABS plastic, nickel plating, electroless plating, RTIL, EMIC.
\end{abstract}

\section{INTRODUCTION}

Plating on plastic is a surface covering of plastics in which a metal is deposited on a conductive surface. Plating is used to decorate objects, for corrosion inhibition, to improve solderability, to harden, to improve wear ability, to reduce friction, to improve paint adhesion, to alter conductivity, to improve IR reflectivity, for radiation shielding, and for other purposes. There are two plating techniques: electroplating and electroless plating [1, 2].

Electroless plating is metal deposition using a controlled chemical reaction. Electroless Nickel (EN) plating is a chemical reduction process, which depends upon the catalytic reduction process of nickel ions in an aqueous solution and the subsequent deposition of nickel metal without the use of electrical energy. Due to its exceptional corrosion resistance and high hardness, the process finds wide application on items such as valves, pump parts etc., to enhance the life of components exposed to severe conditions of service, particularly in the oil field and marine sector. With correct pretreatment sequence and accurate process control, good adhesion and excellent service performance can be obtained from EN deposited on a multitude of metallic and non-metallic substrates. Electroless deposits are therefore very uniform in thickness all over the part's shape and size. This process offers distinct advantages when plating irregularly shaped objects, holes, recesses, internal surfaces, valves or threaded parts [3-6].

\footnotetext{
* Corresponding author. Tel.: +90-232-3111492; fax: +90-232-3887776.

E-mail address: canan.uraz@ege.edu.tr (C. Uraz)
}

The traditional processes mainly include sensitization and activation. The plastic substrate is placed in a sensitizing solution and activation solution during the process. Then the surface adsorbs some discontinuously distributed $\mathrm{Sn}$ as the chemical reductant so that noble metals such as Ag and Pd can be further reduced from the activating solution to serve as the catalyst for the electroless plating. This process is complicated and involves the use of not only poisonous Sn but also noble metallic elements; and the process also produces waste and contributes to pollution [7].

ABS is a low-cost engineering plastic that is easy to machine and fabricate. ABS is an ideal material for structural applications when impact resistance, strength, and stiffness are required. It is widely used for machining preproduction prototypes since it has excellent dimensional stability and is easy to paint and glue. The characteristics are: excellent impact resistance, good machinability, excellent aesthetic qualities, easy to paint and glue, good strength and stiffness, and a relatively low cost $[8,9]$.

Metal plating on the plastic industry is developing rapidly in recent years in the world. There are a lot of importances of the metal-plating on plastics: to be corrosion resistant, increasing the salability of the product with glossy or satin-looking metallic surfaces etc. In most cases, lightweight material characteristic of the plastic provides a major advantage. New types of plastics are stronger, and some are more heat resistant than others, but the lack of hard is the common feature of all. Therefore, the plating of the plastic surface allows the use of longer period of the 
material. Electroless plating is a fundamental step in the metal plating on the plastic. This step makes the plastic conductive and makes it possible to homogeneous and hard plating with desired thickness. It is not magnetic and it is resistant to external influences. Also, because of the high flexibility at the certain rates rupture doesn't happen during the elongation and flexion. Different from electrolytic plating of electroless plating process, the plating process occurs without using current electrical energy. Electroless nickel and copper plating is a coating technique, which relies on reduction of nickel and copper ions with an autocatalytic chemical reduction process, in an aqueous solution containing a reducing agent. In this method, without use of electricity is provided uniform coating thickness on substrates. The method of uniform coating thickness, such as wear and corrosion resistance has a wide range of applications due to their superior properties.

Addition of metallic materials, non-conductive plastic, glass and ceramics can be performed on the electroless nickel and copper plating. Many environmentally hazardous and hazardous chemicals are used for etching of the plastic material, which to be coated with traditional method. Beside the hazards which are exposure of burning chemicals and cyanide, chromium causes cancer risk at especially electrolytic coatings, there are ergonomic hazards and powders that have explosion potential. Instead of them, using the room temperature ionic liquids (RTIL) is objective of this study. Ionic liquids are defined as compounds that are sensitive to the environment due to their low pressure that can be negligible, their high heat resistance, and a higher ionic conductivity, to be electrochemically rich, to have wide open liquid range, to have a range of high polar solubility $[10,11]$. The electroless bath is one of the most important parts of the process. In the industry there are many distinct chemical materials both catalysts and activation solutions. But the cost of the electroplating process is the increasing depends on the activation solutions and catalysts that are imported from the other countries and exactly nonproducing in Turkey. Therefore, the main goal of this study is to investigate the effects of ionic liquids for environmental friendly electroless plating baths in the metal plating industry over ABS plastic. In this way, both it will be provided a significant benefit to public health, and it will be brought innovation to the metal plating industry with the environmental friendly ionic liquid catalyst.

The aim of this study is to plate electroless nickel over ABS plastic using environmentally friendly chemicals. For this purpose, a plating bath was prepared using environmentally friendly chemicals (RTIL: EMIC- 1-ethyl3-methyl imidazolium chloride $\left.\left(\mathrm{C}_{6} \mathrm{H}_{11} \mathrm{~N}_{2} \mathrm{Cl}\right)\right)$ for the nickel plating process on the ABS plastic. Contrary to the traditional processes, the etching and the plating processes were performed with environmentally friendly chemicals. Unlike the electroless nickel plating on metal substrate, the process on ABS substrate is not auto-catalytic. Hence, etching and activation are necessary for initiating the process.

\section{EXPERIMENTAL STUDY}

The experimental study consists of four parts: preparation of the materials, etching, coating, and analysis.
The study was carried out at room temperature in a fume hood. The effects of RTIL as a catalyst, plating time, and sanding paper size were investigated on the nickel plating. Experiments were carried out with 400, 500, and 800 grit sandpaper applying sand attrition process with different bath temperatures of $70{ }^{\circ} \mathrm{C}, 80^{\circ} \mathrm{C}$, and $90^{\circ} \mathrm{C}$, with 30,60 , and 90 minutes of deposition time.

\subsection{Preparation of materials}

Firstly, a $20 \times 30 \times 1.5 \mathrm{~mm}$ piece of ABS plastic was ground with 400, 500, and 800-grit sandpapers to increase the surface area. Then the specimen was placed in a $65^{\circ} \mathrm{C}$ oven and maintained for 4 to $5 \mathrm{~h}$ to remove stress. Afterward then it was immersed in a $10 \mathrm{~g} / \mathrm{L} \mathrm{NaOH}$ alcoholic solution (alcohol: water $=1: 1$ ) and placed in a $40{ }^{\circ} \mathrm{C}$ water bath for 30 min to make the plastic surface basically hydrophilic.

\subsection{Etching}

Afterwards, the specimen was placed in an aqueous solution with a certain ratio of nitric acid $\left(65-68 \% \quad \mathrm{HNO}_{3}\right)(250-300 \mathrm{~mL} / \mathrm{L}), \quad$ hydrogen peroxide $(0.4-0.6 \mathrm{~mol} / \mathrm{L})$ and $\mathrm{NH}_{4} \mathrm{~F}(2-4 \mathrm{~g} / \mathrm{L})$. It was conducted with an ultrasonic wave $(40 \mathrm{kHz}, 100 \mathrm{~W})$ for $30 \mathrm{~min}$ at $25^{\circ} \mathrm{C}$ as a non-noble metal activation pretreatment, using an EAGLE Ultrasonic bath-EU8. The resultant specimen was then washed with deionized water for plating [12]. For the ionic liquid solution, chloride and ionic liquid were weighed with the molar ratio 2:1 and the specimen was immersed in the ionic solution and left for 24 hours [13]. The specimen was then placed in a $70{ }^{\circ} \mathrm{C}$ water bath containing the plating solution.

\subsection{Coating}

Table 1 presents the composition of the solution utilized. $\mathrm{NaOH}$ and $\mathrm{NH}_{3}$ were gradually added during the process to ensure that the $\mathrm{pH}$ of the plating solution was between 8 and 9 . No apparent phenomenon was observed at the initial stage $(10 \mathrm{~min}$ to $20 \mathrm{~min})$. The reaction then produced numerous bubbles for 30 to 40 min. After being washed with deionized water, the final nickel plating specimen was then placed in an oven at $45^{\circ} \mathrm{C}$ to dry.

Table 1. Composition of the electroless plating bath solution

\begin{tabular}{|l|l|c|}
\hline \multicolumn{1}{|c|}{ Chemical } & \multicolumn{1}{|c|}{ Formula } & $\begin{array}{c}\text { Concentration, } \\
\text { g/L }\end{array}$ \\
\hline Nickel chloride & $\mathrm{NiCl}_{2}$ & 20 \\
\hline Sodium hypophosphite & $\mathrm{NaH}_{2} \mathrm{PO}_{2} \cdot \mathrm{H}_{2} \mathrm{O}$ & 24 \\
\hline Sodium citrate & $\mathrm{C}_{6} \mathrm{H}_{5} \mathrm{Na}_{3} \mathrm{O}_{7} \cdot 2 \mathrm{H}_{2} \mathrm{O}$ & 45 \\
\hline Ammonium chloride & $\mathrm{NH}_{4} \mathrm{Cl}$ & 30 \\
\hline
\end{tabular}

\subsection{Characterization of the deposits}

The surface morphology of the deposits (final coating) was investigated using a JEOL-JSM 6060-2003 scanning electron microscope (SEM) with an accelerating potential of $15 \mathrm{kV}$. A JEOL-JSM 6060-2003 scanning electron microscope (SEM) with energy dispersive spectrometer (EDS) working at $15 \mathrm{kV}$ was used to examine the elemental compositions of the deposits.

A RIGAKU D-Max 2200 PC X-ray diffractometer (XRD) was used in $\mathrm{X}$-ray analysis with $\mathrm{CuK} \alpha$ radiation and a Ni filter to analyze the structure of the coating. The 
operating power was $40 \mathrm{kV}$ and $15 \mathrm{~mA}$. Step scanning was used with an interval of $0.02^{\circ}(2 \theta)$ and a residence time of $1 \mathrm{~s}$.

\section{RESULTS AND DISCUSSION}

There was no harmful chemical used in the preparation of the ABS plastic samples, contrary to the traditional etching processes. Instead of using hazardous chemical like palladium and concentrated acid such as sulphuric acid, ethyl alcohol, and sandpaper were utilized. Considering process safety and environmental concerns, electroless nickel plating with environmentally friendly chemicals is a better choice and is in strong demand now.

The effects of RTIL, plating bath temperature, deposition time, and the sand paper size on the plating rate were investigated for the electroless nickel plating.

In general, electroless plating is characterized by the selective reduction of metal ions only at the surface of a catalytic substrate immersed into an aqueous solution of said metal ions, with continued deposition on the substrate through the catalytic action of the deposit itself. Since the deposit catalyzes the reduction reaction, the term autocatalytic is also used to describe the plating process [14].

The literature abounds in the number of possible bath formulations for the electroless deposition of nickel using many different reducing agents and under widely different plating conditions [15]. There are three possible reactions are obtained for nickel/phosphorus baths at the operating range of $60-95^{\circ} \mathrm{C}$ :

$$
\begin{aligned}
& 3 \mathrm{NaH}_{2} \mathrm{PO}_{2}+3 \mathrm{H}_{2} \mathrm{O}+\mathrm{NiSO}_{4} \rightarrow 3 \mathrm{NaH}_{2} \mathrm{PO}_{3}+\mathrm{H}_{2} \mathrm{SO}_{4}+2 \mathrm{H}_{2}+\mathrm{Ni}^{0} \\
& 2 \mathrm{H}_{2} \mathrm{PO}_{2}^{-}+\mathrm{Ni}^{2+}+2 \mathrm{H}_{2} \mathrm{O} \rightarrow 2 \mathrm{H}_{2} \mathrm{PO}_{3}+\mathrm{H}_{2}+2 \mathrm{H}^{+}+\mathrm{Ni}^{0} \\
& \mathrm{Ni}^{2+}+\mathrm{H}_{2} \mathrm{PO}_{2}^{-}+\mathrm{H}_{2} \mathrm{O} \rightarrow \mathrm{Ni}^{0}+\mathrm{H}_{2} \mathrm{PO}_{3}^{-}+2 \mathrm{H}^{+}
\end{aligned}
$$

The metallic nickel is produced at the reactions and the hydrogen production (Eq. 1, Eq. 2, Eq. 3) at the reactions cause the acidity in the bath.

$$
\begin{aligned}
& \mathrm{H}_{2} \mathrm{PO}_{2}^{-}+\mathrm{H}_{\mathrm{ads}} \rightarrow \mathrm{H}_{2} \mathrm{O}+\mathrm{OH}^{-}+\mathrm{P} ; \\
& 3 \mathrm{H}_{2} \mathrm{PO}_{2}^{-} \rightarrow \mathrm{H}_{2} \mathrm{PO}_{3}^{-}+\mathrm{H}_{2} \mathrm{O}+2 \mathrm{OH}^{-}+2 \mathrm{P} .
\end{aligned}
$$

As shown in Eq. 4 and Eq. 5, phosphorus is produced with nickel. The coating consists of $3-15 \%$ Ni-P alloy at the nickel/phosphorus baths. Alkaline baths are ideal for coating at lower temperature and they are generally used for the coating of plastic material such as ABS [16].

The thicknesses of deposit on the ABS plastics were determined by using Fischerscope X-Ray XDL-B System. The effects of the plating bath temperature and plating time on the amount of deposit are shown in Fig. 1. It can be seen from Fig. 1 that, the thickness of deposit increased with the increasing plating time of the substrate at any temperature. In addition, the thickness of deposit increased with the increasing temperature. The maximum thickness of the deposit was found as $5.010 \mu \mathrm{m}$ for $80^{\circ} \mathrm{C}$ and $90 \mathrm{~min}$ using EMIC, but the deposit was about $0.293 \mu \mathrm{m}$ for $70^{\circ} \mathrm{C}$ and $0.804 \mu \mathrm{m}$ for $90{ }^{\circ} \mathrm{C}$. It can be said that the plating bath solution decomposed because of the temperature increase and the extremely high reaction rate reduction before the maximum thickness of deposit was achieved.

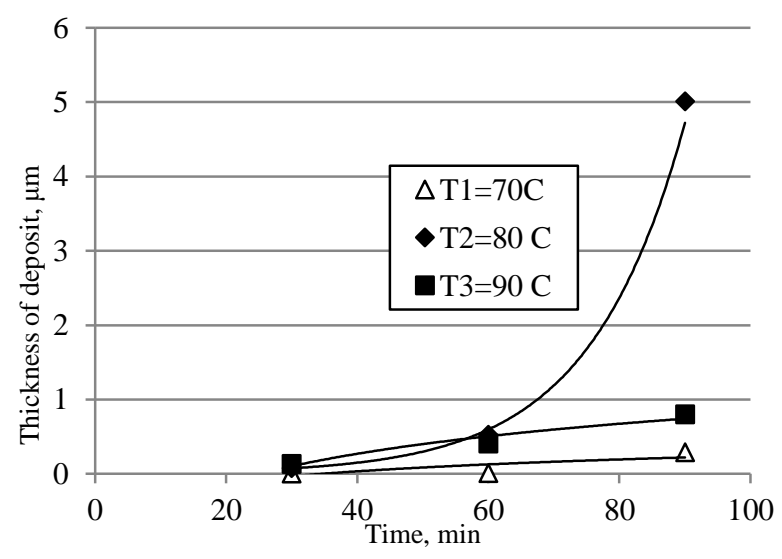

Fig. 1. Effects of plating time and bath temperature on the thickness of deposit for electroless nickel plating with EMIC

The effects of the plating bath temperature and plating time on the thickness of deposit were investigated for electroless Ni-plating without an ionic liquid (EMIC) (Fig. 2). The maximum thickness of deposit was about $1.74 \mu \mathrm{m}$ for $80{ }^{\circ} \mathrm{C}$ and $30 \mathrm{~min}$, but the deposit was about $0.027 \mu \mathrm{m}$ and $0.784 \mu \mathrm{m}$ for $90{ }^{\circ} \mathrm{C}$; and the thickness of deposit decreased with the increasing plating time of the substrate at each temperature for plating without EMIC.

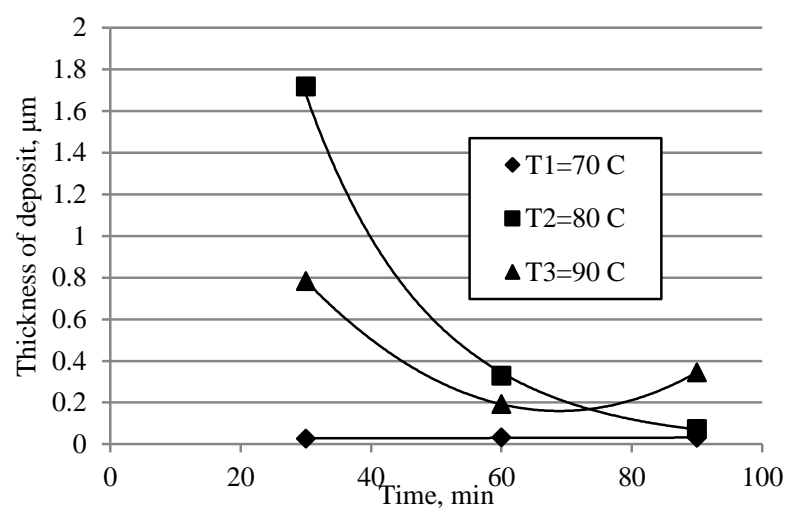

Fig. 2. Effects of plating time and bath temperature on the thickness of deposit for electroless nickel plating without EMIC

The effect of sandpaper size on the thickness of deposit was also investigated and it is presented in Fig. 3.

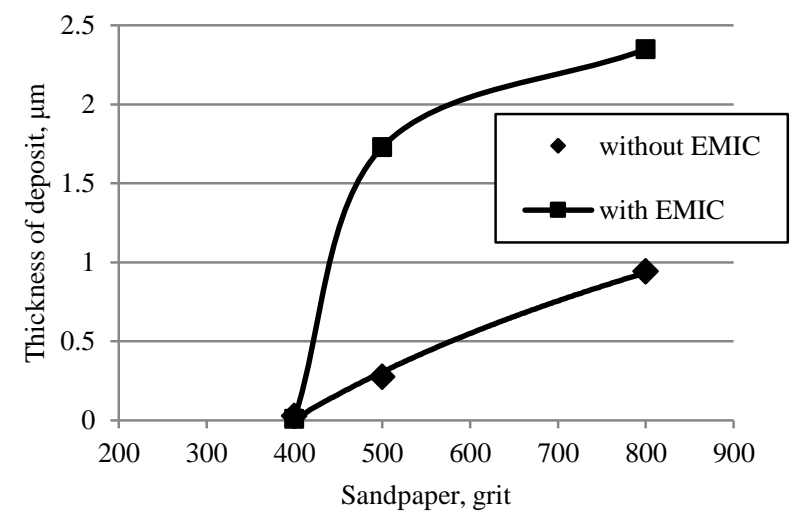

Fig. 3. The effect of sandpaper size on the thickness of deposit at $70{ }^{\circ} \mathrm{C}$ and at a $\mathrm{pH}=8-9$ for 30 minute of plating time 
According to the results of the experiments, three of the samples that gave the best plating results in X-ray analysis were analyzed using XRD and SEM-EDS.

The plated specimen was qualitatively identified by XRD. The observed diffraction peaks of the plated film agreed with those of nickel in the literature [17], as shown in Fig. 4. It also reveals the absence of other elements' diffraction peaks, which states that the plating only includes Ni. Comprehensive analysis indicates that nickel plating on the plastic surface after the new activation pretreatment using environmentally friendly chemicals is completely feasible.

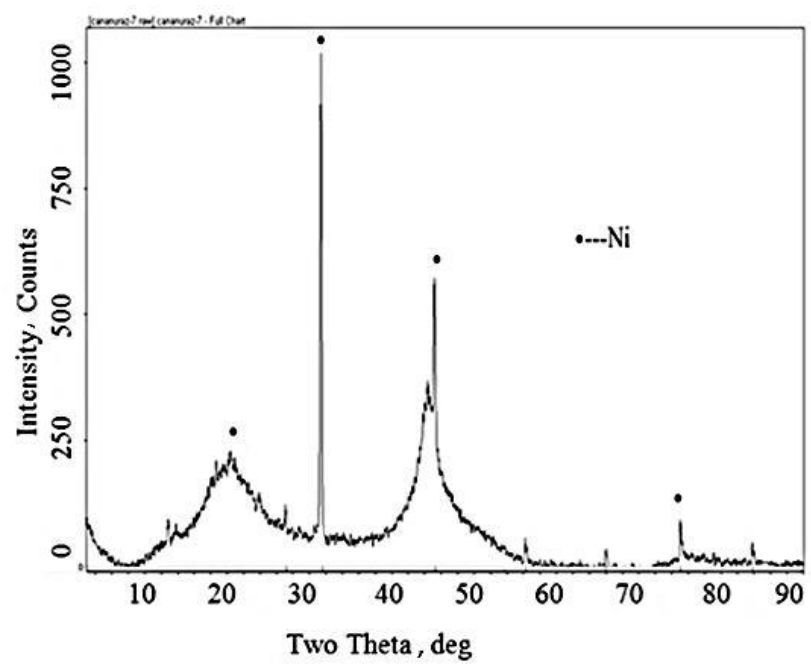

Fig. 4. XRD pattern of electroless Ni-plating with EMIC using 800 grit sandpaper at 30 minutes plating time

A SEM analysis was performed for the surface of the nickelplated specimen using RTIL. Morphology of deposits are shown in Fig. 5, so material was deposited on the surface of the substrate and this proves that electroless plating took place. The elemental mapping result using SEM-EDS also indicated that the plating film consisted of nickel only, and the nickel was homogeneously distributed on the surface of the film Table 2 .

Table 2. The elemental mapping result using SEM-EDS

\begin{tabular}{|c|c|c|c|c|}
\hline \multicolumn{2}{|c|}{ Component } & Mole, Conc. & Conc. & \\
\hline \multicolumn{2}{|c|}{$\mathrm{Cl}$} & 12.328 & 14.869 & wt.\% \\
\hline \multicolumn{2}{|l|}{$\mathrm{Na}$} & 9.612 & 7.518 & wt.\% \\
\hline \multicolumn{2}{|l|}{$\mathrm{P}$} & 26.522 & 27.948 & wt. $\%$ \\
\hline \multicolumn{2}{|l|}{$\mathrm{Ni}$} & 18.011 & 35.965 & wt. $\%$ \\
\hline \multicolumn{2}{|l|}{$\mathrm{C}$} & 33.527 & 13.700 & wt. $\%$ \\
\hline & 100.00 & 100.00 & wt. $\%$ \\
\hline Elt. & Line & Intensity, c/s & Error, 2-sig & Conc. \\
\hline $\mathrm{C}$ & $\mathrm{Ka}$ & 2.38 & 0.308 & 13.70 \\
\hline $\mathrm{Na}$ & $\mathrm{Ka}$ & 10.89 & 0.660 & 7.51 \\
\hline $\mathrm{P}$ & $\mathrm{Ka}$ & 65.90 & 1.624 & 27.94 \\
\hline $\mathrm{Cl}$ & $\mathrm{Ka}$ & 29.99 & 1.095 & 14.86 \\
\hline \multirow[t]{2}{*}{$\mathrm{Ni}$} & $\mathrm{Ka}$ & 14.06 & 0.750 & 35.96 \\
\hline & & & & 100.00 \\
\hline \multicolumn{5}{|c|}{$\begin{array}{l}\mathrm{kV}-15 \\
\text { Take off angle }-35.00 \\
\text { Elapsed livetime }-100.0\end{array}$} \\
\hline
\end{tabular}
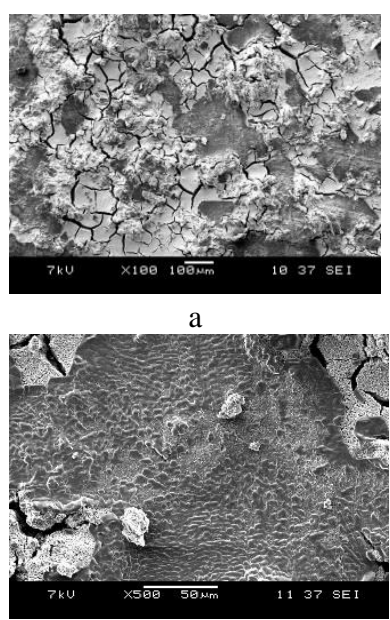

c

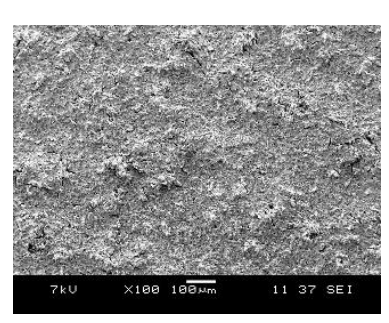

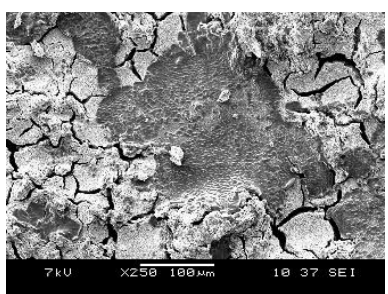

b

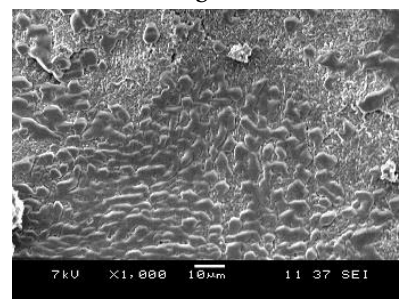

d
Fig. 5. SEM analysis of the sample which was obtained using: a, b, c-EMIC with 800 grit size sandpaper at 30 minutes; $\mathrm{d}$ - with 320 grit size sandpaper at 30 minutes; $\mathrm{e}$ - with 800 grit size sandpaper at 60 minutes

\section{CONCLUSIONS}

1. In this study electroless nickel plating on ABS plastic was achieved at different plating times and thickness using with EMIC and without EMIC.

2. Contrary to the conventional sensitization and activation steps, the palladium-free surface activation process was used to activate the ABS plastic. After nickel plating, the pretreated plastic surface obtained a uniformly distributed Ni coating.

3. This study succeeded in demonstrating the electroless plating of dense, smooth, and pure nickel from an RTIL, EMIC. The XRD results indicated that the deposited film was nickel. The elemental mapping results of the SEM-EDS indicated that the plating film consisted of nickel only, and the nickel was homogeneously distributed on the surface of the film.

4. The long-term impact of this study may be towards the development of a simple and effective method for a palladium-free surface activation process to improve the activity of the surface of plastics.

5. An activation solution containing acid and salt without any $\mathrm{Sn}$ or Pd (Ag) was utilized and ultrasonic treatment of the surfaces of the ABS plastic was expected to produce the necessary surface defects which serve as the active sites for the direct electroless nickel plating.

6. This new electroless plating process is considerably simpler when compared with the currently used traditional methods and does not involve any noble or poisonous metals as well as any expensive equipment which may reduce the process cost and environmental pollution significantly. 


\section{Acknowledgments}

The author acknowledges the financial support from the Scientific and Technological Research Council of Turkey (TUBITAK) under project number 216M372 and Ege University Scientific Research Fund under project no. 16MUH129 and 18BIL005.

\section{REFERENCES}

1. https://en.wikipedia.org/wiki/plating (Access date: March, 2017).

2. Fukuhara, C., Ohkura, H., Gonohe, K., Igarashi, A. LowTemperature Water-Gas Shift Reaction of Plate-Type Copper-Based Catalysts on an Aluminum Plate Prepared by Electroless Plating Applied Catalysis A: General 279 2005: pp. $195-203$.

https://doi.org/10.1016/j.apcata.2004.10.036

3. https://advancedplatingtech.com/plating-topics/advantageselectroless-electrolytic-nickel/ (Access date: June, 2016).

4. Sha, W., Wu, X., Keong, K.G. Electroless Copper and Nickel-Phosphorus Plating. Woodhead Publishing, 2011: pp. $141-154$. https://doi.org/10.1533/9780857090966

5. http://www.corrosiondoctors.org/MetalCoatings/Electroless.htm (Access date: April, 2017).

6. http://www.pfonline.com/articles/electroless-nickel-plating (Access date: April, 2017).

7. Caturla, F., Molina, F., Molina-Sabio, M., RodriguezReinoso, F., Esteban, A., Electroless Plating of Graphite with Copper and Nickel Journal of Electrochemical Science 142 1995: pp. 4084-4091. https://doi.org/10.1149/1.2048468

8. https://plastics.ulprospector.com/generics/1/acrylonitrilebutadiene-styrene-abs) (Access date: April, 2017).

9. http://serc.carleton.edu/research_education/geochemsheets/t echniques/XRF.html (Access date: April, 2017).
10. Marsh, K.N., Boxall, J.A., Lictenthaler, R., Room Temperature Ionic Liquids and Their Mixtures-a Review Fluid Phase Equilibria 219 2004: pp. 93-98. https://doi.org/10.1016/j.fluid.2004.02.003

11. Endres, F., MacFarlane, D., Abbott, A. Electrodeposition from Ionic Liquids, Wiley-VCH, Weinheim, Germany, 2008. https://doi.org/10.1002/9783527622917

12. Luo, L.M., Lu, Z., Huang, $X$., Tan, $X$., Ding, $X$., Cheng, J., Zhu, L., Wu, Y. Electroless Copper Plating on PC Engineering Plastic with a Novel Palladium-Free Surface Activation Process Surface \& Coating Technology 251 2014: pp. $69-73$. https://doi.org/10.1016/j.surfcoat.2014.04.005

13. Koura, N., Nagase, H., Sato, A., Kumakura, S., Takeuchi, K., Ui, K., Tsuda, T., Loong, C.K. Electroless Plating of Aluminum from a Room-Temperature Ionic Liquid Electrolyte Journal of Electrochemical Society 155 2007: pp. $155-157$. https://doi.org/10.1149/1.2817880

14. Mallory, G.O., Hadju, J.B. Electroless Plating Fundametals \& Applications, 1st edition, USA, William Andrew Publishing, 1990: p. 538. https://www.elsevier.com/books/electrolessplating/mallory/978-0-8155-1277-6

15. Schlesinger, M., Paunovic, M. Modern Electroplating, 5th edition, New Jersey John Wiley \& Sons, Inc., 2010: p. 729.

16. Kılıçarslan, A., Toptan, F., Kerti, I. Akımsız Nikel Kaplama Yöntemi ve Seramik Partiküllerine Uygulanmas1, Türk Mühendis ve Mimar Odaları Birliği Metalurji Mühendisleri Odas1, http://www.metalurji.org.tr/dergi/ dergi154/ d154_3337.pdf (Access Date: 5.11.2016).

17. Tang, X., Bi, C., Han, C., Zhang, B. A New Palladium Free Surface Activation Process for Ni Electroless Plating on ABS Plastic Materials Letters 63 2009: pp. 840-842. https://doi.org/10.1016/j.matlet.2009.01.006 